\title{
A device for rainfall simulation in geotechnical centrifuges
}

\author{
Shun Wang ${ }^{1}$ (D) Gregor Idinger $^{1}$
}

Received: 16 December 2020/Accepted: 9 March 2021 / Published online: 15 April 2021

(C) The Author(s) 2021

\begin{abstract}
Rainfall-induced slope instabilities are ubiquitous in nature, but simulation of this type of hazards with centrifuge modelling still poses difficulties. In this paper, we introduce a rainfall device for initiating slope failure in a medium-sized centrifuge. This rainfall system is simple, robust and affordable. An array of perforated hoses is placed close above the model slope surface to generate the raindrops. The rainfall intensity depends on the centrifuge acceleration and the flow rate of the water supply, which is controlled by the size and number of the tiny pinholes in the hose walls. The rainfall intensities that are tested range from $2.5-30 \mathrm{~mm} / \mathrm{h}$, covering the intensity range of moderate, heavy and torrential rainfall events. Our model test with rainfall-induced slope failure shows that this system is capable of generating relatively uniform rainfall of wide intensities and leads to various patterns of slope failure.
\end{abstract}

Keywords Centrifuge model test $\cdot$ Rainfall simulation $\cdot$ Slope stability $\cdot$ Partially saturated soil

\section{Introduction}

Geotechnical centrifuge modelling is widely used to investigate rainfall-induced slope failure. One of the main difficulties associated with the model test is the simulation of artificial rainfall. Several methods have been developed to simulate artificial rainfall with a uniform intensity over the entire slope surface. The first attempt on rainfall-induced slope failure in a centrifuge model was made by Kimura [9]. Since then, various rainfall systems have been introduced by, e.g., standard nozzles with droplet diameters in the order of magnitude of millimetres [7], mist spay nozzles or atomizing nozzles operated with high back pressures $[6,11,15,16]$, spaying water mist by hand [10], and a single water source at the slope shoulder as subsurface flow to initiate base liquefaction [13, 14].

Among the aforementioned methods, the spray nozzle is the most popular device to generate artificial rainfalls. By changing the number of nozzles and discharge rates, desirable rainfall intensities can be achieved. However, the use of nozzle has some problems, which are summarized in

Shun Wang

shun.wang@boku.ac.at

1 Institut für Geotechnik, Universität für Bodenkultur Wien, Feistmantelstrasse 4, 1180 Vienna, Austria
Fig. 1. Most nozzles cover a circular area, which makes it difficult to generate uniform rainfall. In the enhanced acceleration field, nozzles often produce a core zone with a higher rainfall intensity than the outside areas. Moreover, the nozzles are often placed several centimetres above the slope surface and the falling height makes the raindrops vulnerable to the Coriolis effect, which may alter the falling path of the raindrops. Another major concern is the impact force produced by the raindrops. During the centrifuge test, the raindrops may give rise to substantial compaction and erosion on the soil surface. The effect of rainfall in centrifuge is also influenced by other factors, such as drag forces, evaporation and artificial wind above the slope surface [2].

The characteristics of the artificial rainfall depend on the centrifuge acceleration, nozzle position and direction, injection pressure, wind velocity, raindrop size, etc. [3]. To minimize the impact of these factors and obtain uniform rainfall on the slope surface, a set of mist nozzles needs to be arranged properly in position and direction, depending on the shape of the model. All the nozzle types require a minimum falling height of several centimetres to cover a certain area, and fine mist spray nozzles with fine droplets are often used to minimize the impact force. However, for some centrifuge facilities with limited space, it is difficult to accommodate the required equipment of pressure-regulated containers of several bars, which is required even for 

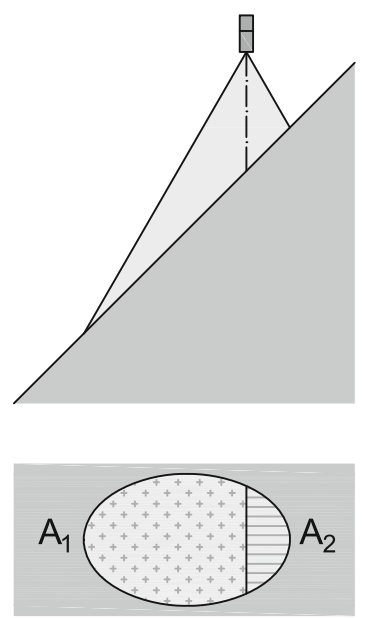

Rainfall amount: $A_{1}=A_{2}$ Rainfall intensity: $A_{1}<A_{2}$
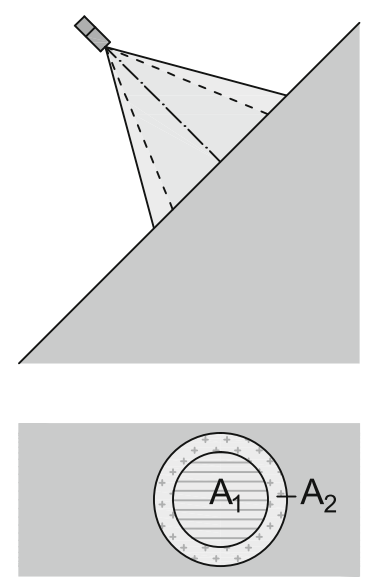

Rainfall intensity: $A_{1}>A_{2}$
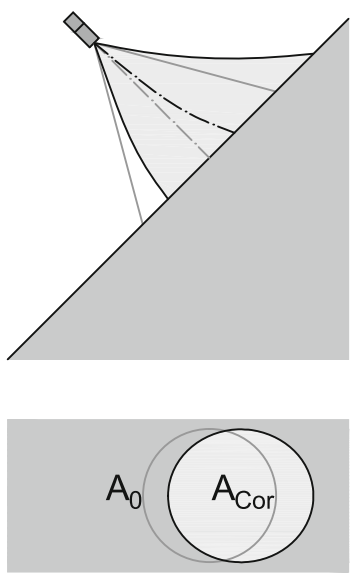

Coriolis effect (depend on model orientation)

Fig. 1 Problems with nozzles for rainfall simulation on an inclined plane, illustrated for a single nozzle

the one-phase mist nozzles at low flow rates. Regular nozzles operating at lower pressures are not an option, as the larger droplet size would impose destructive impact forces on the soil surface from the large falling height. Hence, it is necessary to develop a simple rainfall device for centrifuge facilities free of pressurized water connections for operating mist nozzles.

In this paper, a rainfall device for initiating slope instabilities in centrifuge model tests is introduced. The system is developed in accordance with the principle of drip irrigation by using an array of perforated hoses placed close above the slope surface. The rainfall intensity is mainly dictated by the size and number of the perforations. Two types of pinholes are applied to produce droplets with different sizes. The flow rate and rainfall intensity of the system are calibrated in the centrifuge facility at different $g$ levels. Finally, some centrifuge tests on rainfall-induced slope failure are presented to show the performance of the rainfall system.

\section{Centrifuge facility and model box}

The rainfall system is developed for the beam-type centrifuge testing facility in our laboratory. A schematic illustration of our centrifuge is presented in Fig. 2. The centrifuge has a nominal radius of $1.31 \mathrm{~m}$. The swinging platforms are located at both ends of the symmetrical beam, one for the model and the other for the counterweight.

The model slope is tested in a plane-strain model box, as shown in Fig. 3. The model box is mainly made of aluminium alloy and has the inner dimensions of
$480 \times 155 \times 450 \mathrm{~mm}(\mathrm{~W} \times \mathrm{D} \times \mathrm{H})$. The top plate has recess holes for the sensors and water supply hoses. The base plate is rigidly connected to the swinging platform. A transparent front wall of acrylic is used as an observation window to view the side profile of the model slope. The model container is equipped with a digital camera in front of the observation window to track the in-plane soil displacement. Photographs are taken every 10 seconds with a resolution of $2592 \times 1944$ pixels. To maintain undisturbed plane-strain conditions, the friction between the soil and the rear and the acrylic front wall should be minimized. For this purpose, a thin film of transparent silicon oil is applied on the inner surface of the front and rear wall prior to each test. This lubricant reduces the wall friction and minimizes its effect on the soil deformation.

\section{Rainfall system for centrifuge modelling}

\subsection{Components of the rainfall system}

The new rainfall system consists of a storage tank for rainwater, a water line connecting the tank to the model box and a distribution system with perforated hoses located in close vicinity above the soil surface. In the system, rainfall can be initiated and stopped by a solenoid valve. Figure 4 shows the main components of the rainfall system.

\subsubsection{Water tank and supply line}

Due to the lack of a slip-ring connection for pressurized water, the water for the rainfall system has to be stored and pressurized in the centrifuge. A cylindrical plastic 


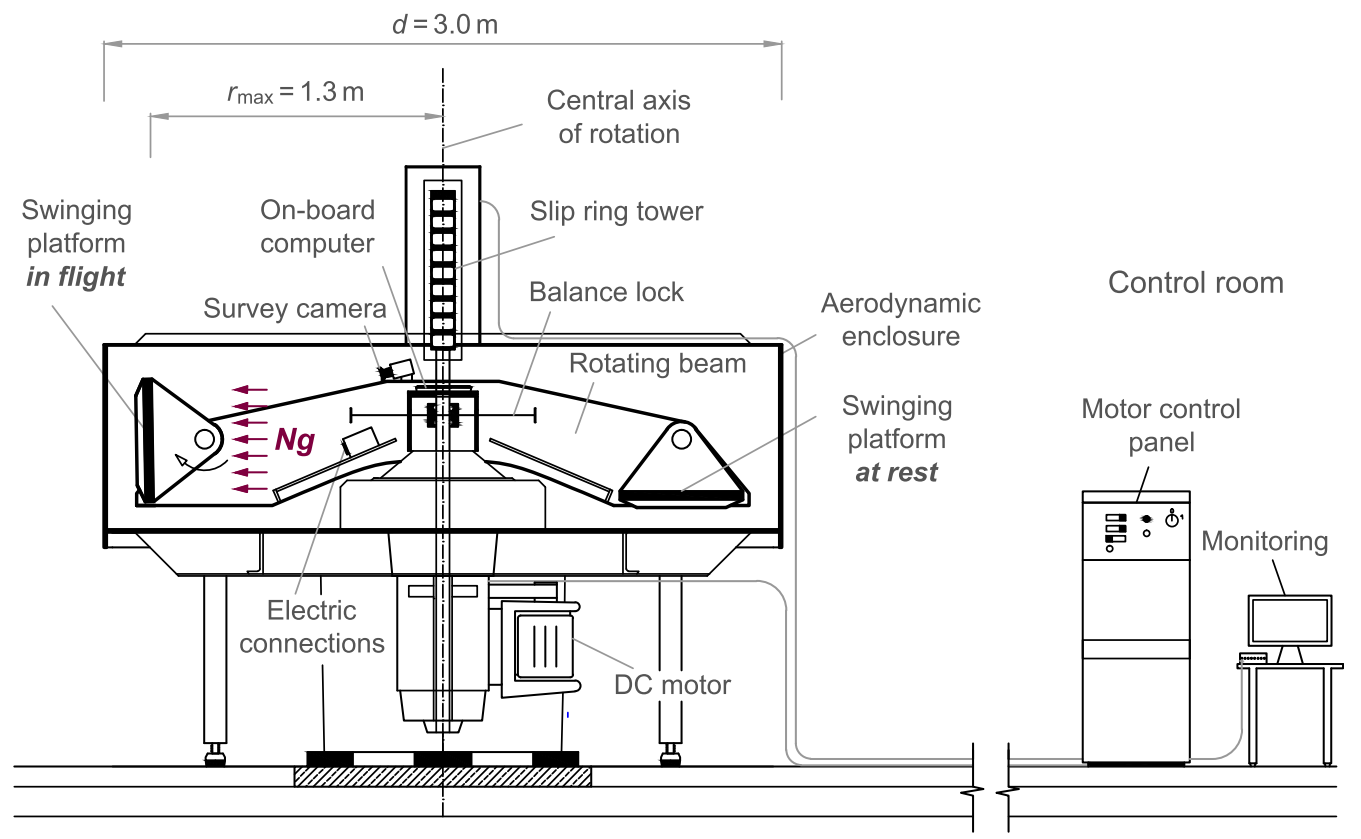

Fig. 2 Schematic presentation of the centrifuge testing facility

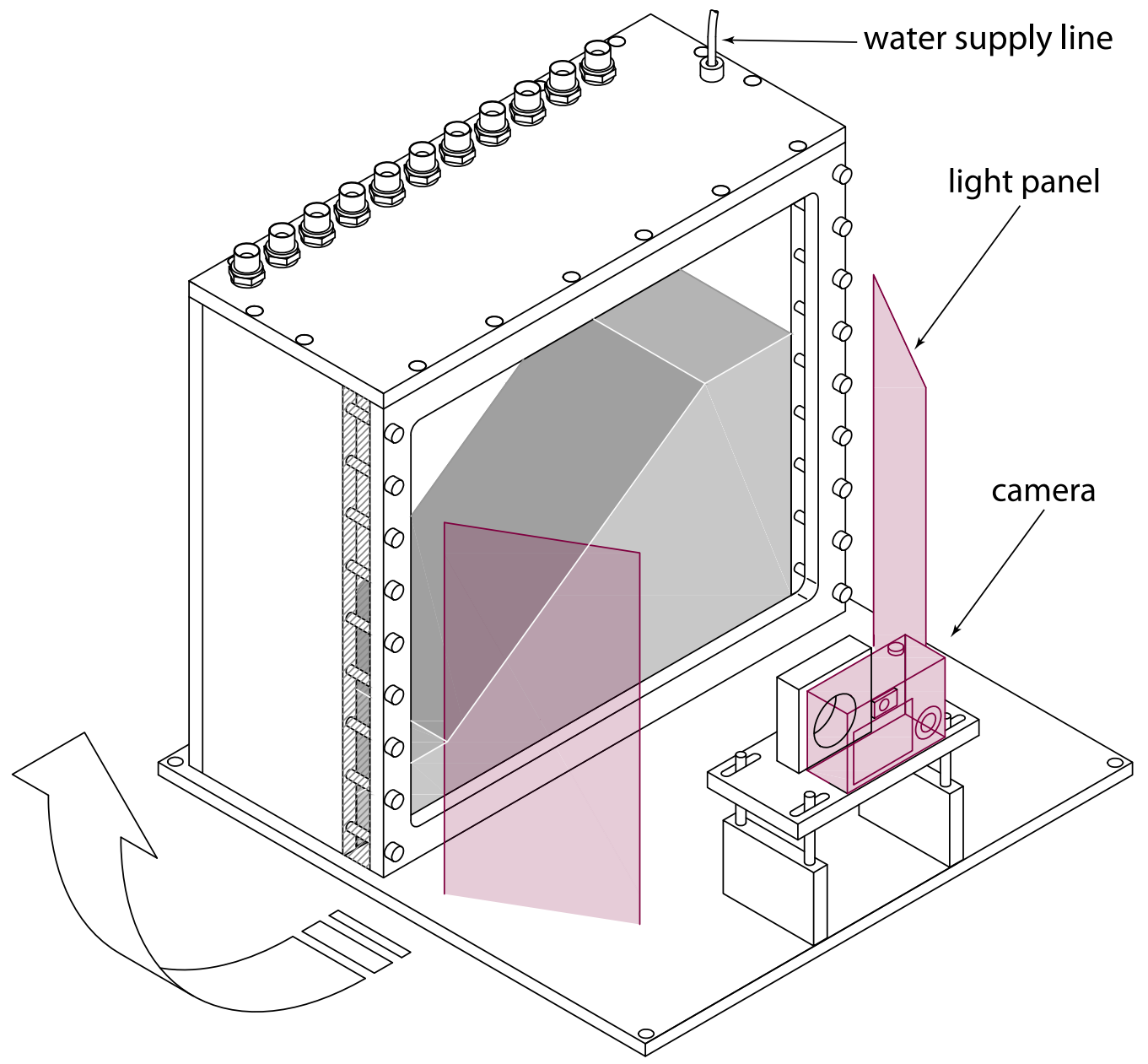

Fig. 3 Sketch of the model box with a camera and light panels 


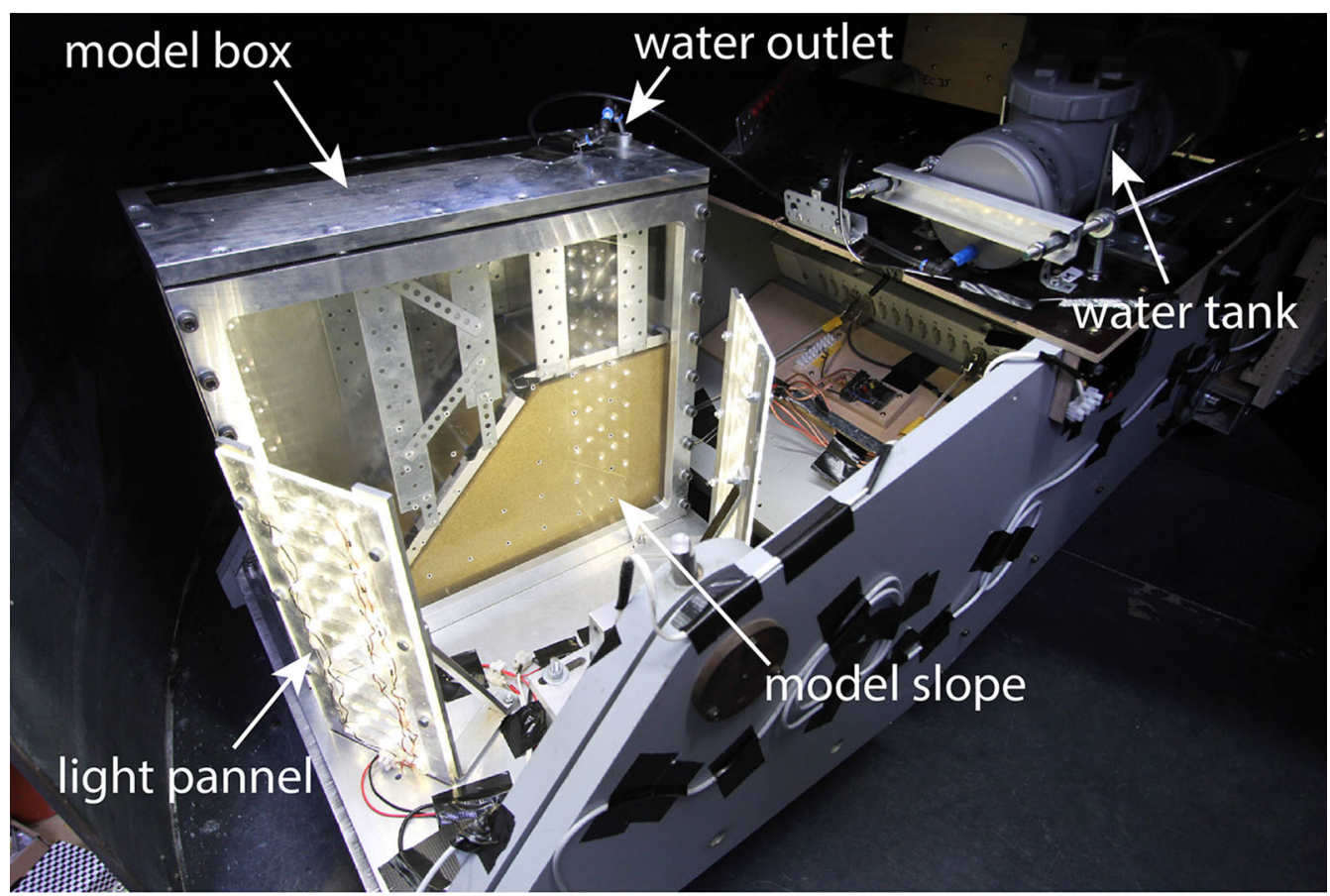

(a)

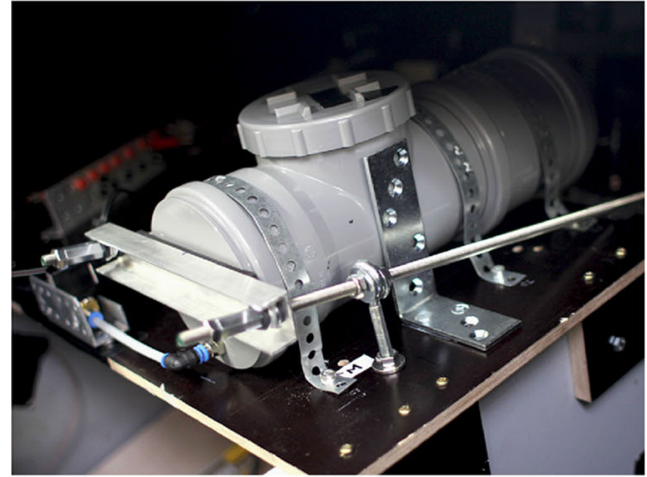

(b)

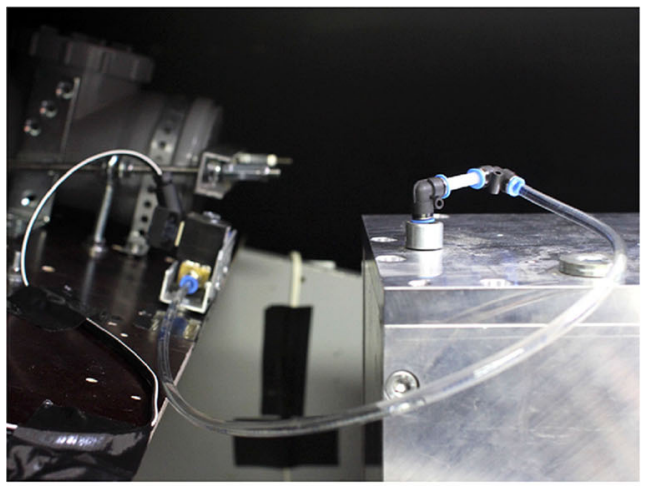

(d)

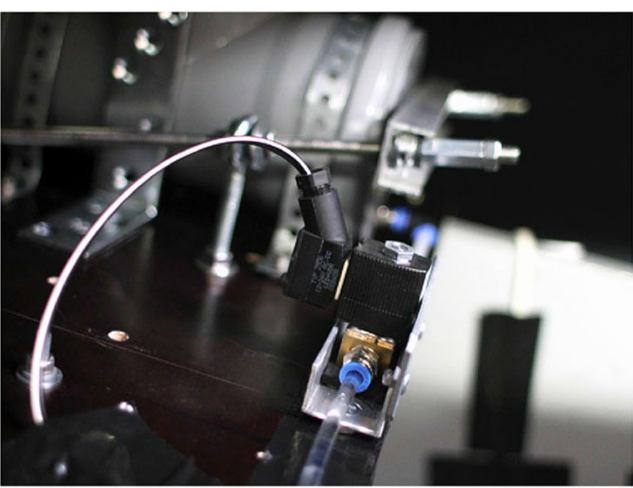

(c)

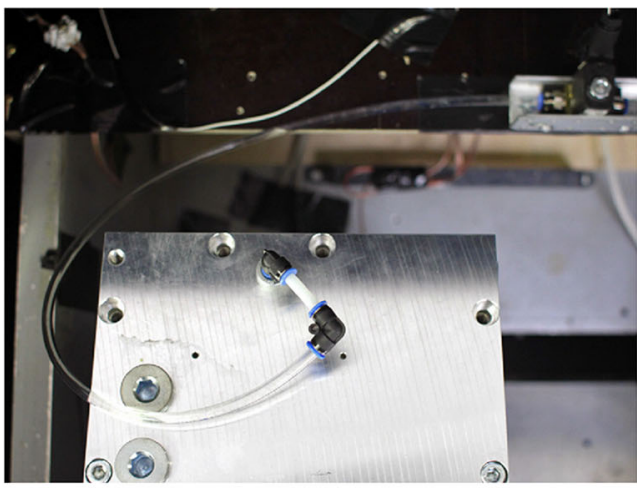

(e)

Fig. 4 Pictures of the rainfall system a water storage and distribution system, $\mathbf{b}$ water tank, $\mathbf{c}$ solenoid valve, $\mathbf{d}$ flexible connecting hose and e inlets of the model container

container with an inner diameter of approximately $100 \mathrm{~mm}$ and a length of approximately $350 \mathrm{~mm}$ is employed as the water tank, with a maximum volume of $2750 \mathrm{ml}$ (see Fig. 4b). The tank features a large reclosable opening on 
the top, which is used to refill the tank in place. When the outflow is activated, a small hole at the back side of the tank prevents the generation of vacuum and exposes the free water surface inside the tank to the atmospheric pressure. The tank is mounted near the pivot of the centrifuge to minimize the centrifuge force, and the water in the tank is exposed to accelerations of approximately 0.5 $\mathrm{N}\left(\mathrm{kg} \cdot \mathrm{m} / \mathrm{s}^{2}\right)$. The generated pressure in the water supply system depends on the centrifuge acceleration, with approximately $120-170 \mathrm{kPa}$ at $30-\mathrm{g}$ level.

The onset of artificial rainfall is controlled by a solenoid valve from the control panel. The selected 2/2-way miniature solenoid valve is closed by default and can operate at water pressures up to $300 \mathrm{kPa}$. The rainfall system behind the valve is initially dry. When activated, the valve allows a maximum flow rate of approximately $2170 \mathrm{ml} / \mathrm{min}$. Under $1-g$ conditions, this corresponds to a maximum rainfall intensity of $2370 \mathrm{~mm} / \mathrm{h}$ for the covered area of approximately $550 \mathrm{~cm}^{2}$. When deactivated, a small amount of water drips as the line behind the valve is emptied. The time at which the valve is opened and closed is recorded, and the short delay of rainfall initiation is filmed by the camera placed inside the model box. After the test, the amount of rainwater can be calculated from the remaining water in the water tank. In combination with the rainfall duration, the rainfall intensity can be defined for each test.

\subsubsection{Rainfall perforated hoses}

As shown in Fig. 5, the perforated hoses are aligned parallel to the slope toe line. The horizontal spacing between two adjacent hoses is $35 \mathrm{~mm}$. This spacing is chosen based on infiltration tests to allow sufficiently uniform infiltration front. The hoses are connected to the railings at both ends. The railings with the water supply mains are fixed to the front and rear wall of the model box. To follow the geometry of the slope, two sets of perforated hoses are used, one for the crest and the other one for the inclined slope section. This configuration leads to different number of perforated hoses at the crest and the slope section. For instance, for a $35^{\circ}$ slope, seven perforated hoses are placed above the slope section and the remaining three are fixed at the crest, while for a $45^{\circ}$ slope, the same number of perforated hoses is distributed at the crest and the slope section (see Figs. 5b, c). The perforated hoses are located approximately $10 \mathrm{~mm}$ above the slope surface. This short falling height is adopted to minimize the impact force of the raindrops and the Coriolis effect. With an inner diameter of $2.5 \mathrm{~mm}$ and wall thickness of $0.75 \mathrm{~mm}$, the perforated hose is durable enough to withstand considerable deformations when subjected to enhanced gravity forces.

The rainfall intensity is regulated by the number and orifice diameter of the dripping outlets arrayed on the hose walls. To generate describable rainfall intensities, two types of perforated hose with different sizes of pinholes are used in this system. The smaller pinhole produced by tiny minute pins of stainless steel represents the low-flow I-type. A relative larger needle is used to produce the high-flow II-type pinhole. These tiny minute pins and needles are fixed on a hole puncher, which can generate a uniform size of the pinholes through standardized production. To guarantee constant flow rates throughout the rainfall simulation, the pinholes are uniformly distributed on the hose walls.

Figure 6 shows the close-up images of the pinpoints for both types. The shape of the pinholes is determined by the diameter and shape of the needle tip. Specifically, the conically shaped pinpoints give rise to an outside diameter $d_{\text {out }}$ and an inside diameter $d_{\text {in }}$ of a pinhole, with the latter one governing the flow rate of the pinhole. Table 1 summarizes the basic characteristics of both types of pinholes. The flow rates of a single pinhole at 30-g are approximately

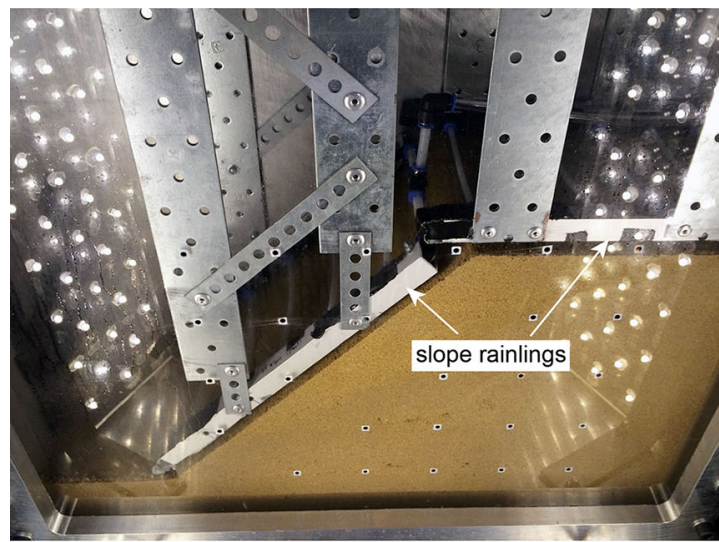

(a)

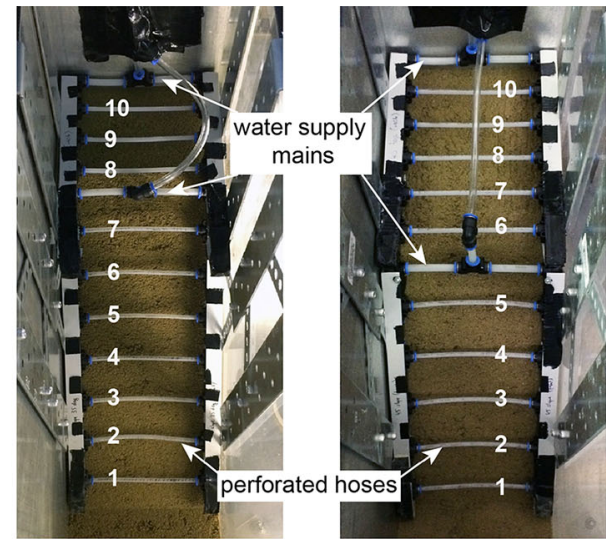

(b) (c)

Fig. 5 Distribution of the perforated hoses for rainfall simulation: a side view and top views for slopes with gradients of $\mathbf{b} 35^{\circ}$ and $\mathbf{c} 45^{\circ}$ 

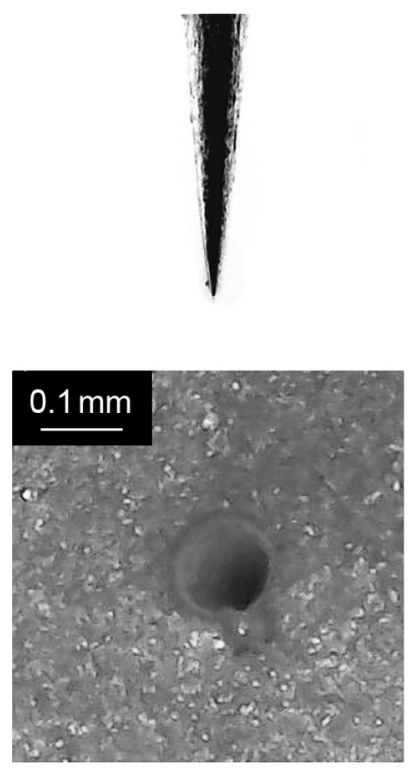

I-type Pinhole

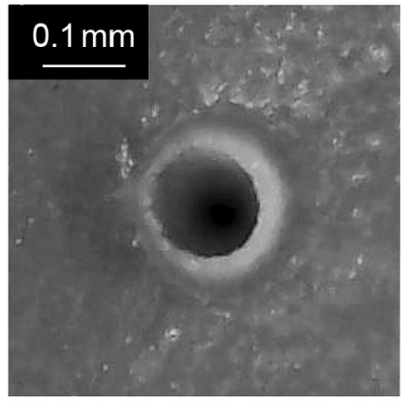

II-type Pinhole
Fig. 6 Close-up images of the pinpoints used to produce the I-type and II-type pinholes in the hose walls

Table 1 Properties of the pinholes on the hose walls

\begin{tabular}{lll}
\hline Index & I-type & II-type \\
\hline$d_{\text {in }}[\mu \mathrm{m}]$ & 69 & 113 \\
$d_{\text {out }}[\mu \mathrm{m}]$ & 133 & 184 \\
Flow rate of 1 pinhole at $30-g[\mathrm{ml} / \mathrm{min}]$ & 1.74 & 3.12 \\
Rainfall intensity of 1 pinhole $30-g[\mathrm{~mm} / \mathrm{h}]$ & 0.64 & 1.07 \\
\hline
\end{tabular}

$1.74 \mathrm{ml} / \mathrm{min}$ and $3.12 \mathrm{ml} / \mathrm{min}$ for the I-type and II-type pinholes, respectively. The inner diameter of the II-type pinhole is approximately $113 \mu \mathrm{m}$, which is sufficiently small to generate tiny raindrops over the slope surface.

The behaviour of the raindrops in the enhanced acceleration field is investigated by employing a high-speed camera during the flight of the centrifuge . It is observed that the diameters of the raindrops at 30- $g$ are approximately $500 \mu \mathrm{m}$. The raindrops are accelerated to an impact velocity of approximately $0.7 \mathrm{~m} / \mathrm{s}$. With the density and impact velocity of the raindrops, the impact force is estimated to be $10 \mathrm{~Pa}$ in accordance with the equation proposed by Tamate et al. [16]. Moreover, the defection raindrop path is found to be negligible as a result of the short falling height. To make sure no pinholes are clogged prior to the rainfall simulation, it is recommended to clear the perforated hoses using pressured deionized water.

\subsection{Calibration}

The rainfall intensity and flow rate of the rainfall system are calibrated by employing different numbers of pinholes (with both I-type and II-type ) at each hose. Six configurations with different number of pinholes at each hose are calibrated in the centrifuge at various $g$ levels. The rainfall intensity is calibrated by collecting the accumulated rainwater discharged by all perforated hoses in 10 minutes. To minimize the system errors, four parallel tests are carried out for each configuration. Moreover, the influence of the pressure head of the rainwater on the uniformity of the rainfall distribution is evaluated by measuring the discharge of each perforated hose. To this end, the rainwater produced by each perforated hose in 30 seconds is collected by plastic bags during the calibration. Figure 7 shows the setup of the rainfall system in the model box and the rainfall intensity during the calibration tests.

The calibration results are presented in Fig. 8. As suggested by Fig. 8a, the flow rate for low rainfall intensities, i.e. $I_{\mathrm{P}}=2.0-15.0 \mathrm{~mm} / \mathrm{h}$, is mainly governed by the number of pinholes, while for higher rainfall intensities tested up to $30.0 \mathrm{~mm} / \mathrm{h}$, the flow rate is governed by the diameter of the pinholes. For example, a rainfall intensity of $15.0 \mathrm{~mm} / \mathrm{h}$ is achieved by ten perforated hoses, each with 25 I-type pinholes, each of which covers an area of approximately $2.0 \mathrm{~cm}^{2}$. As shown in Fig. 8 b, with the same number of water outlets, the rainfall intensities resulting from I-type and II-type pinholes vary considerably. Moreover, by adjusting the number of pinholes, a desired rainfall intensity can be achieved by the system.

The flow rates of each perforated hose in two parallel tests are presented in Fig. 8c. It shows that similar discharges are produced throughout all the perforated hoses. Only the hoses located at the toe of the slope give rise to more rainwater due to the relatively higher pressure head. On the other hand, the water stored in the supply mains may also contribute to this result. When evacuating the rainfall system, the supply mains may discharge the residual water from the lowest position of the system to the rainwater storage. Nevertheless, the flow rates of all the perforated hose show considerable consistency, so that check valves for adjusting the flow rates at different slope elevation are not required along the supply mains. Figure $8 \mathrm{~d}$ shows the rainfall intensity and discharge of ten perforated hoses, each with 25 I-type pinholes, at various $g$ levels. An inspection of the results suggests an decreasing relation between rainfall intensity against $g$ level. This result is directly related to the scaling law.

Up to now, there lacks a universally recognized definition of scaling law for the velocity and discharge of rainwater in centrifuge modelling [17]. Generally, the velocity is scaled proportional to 1 for dynamic events and by $N$ for fluid flows in porous media, such as consolidation or seepage processes. Some researchers [1, 8, 12], however, proposed a scaling factor of $\sqrt{N}$ for fast granular flows at 


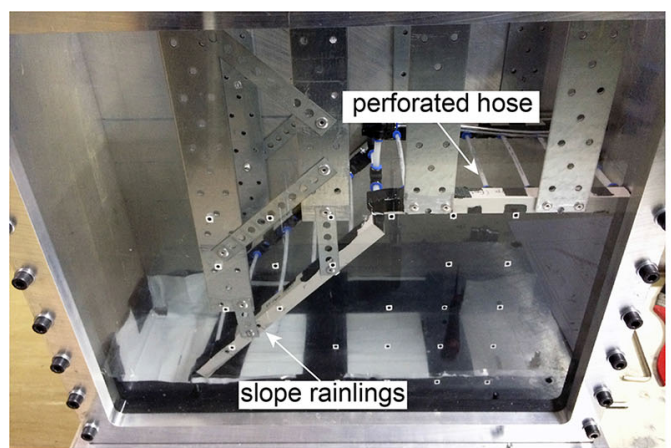

(a)

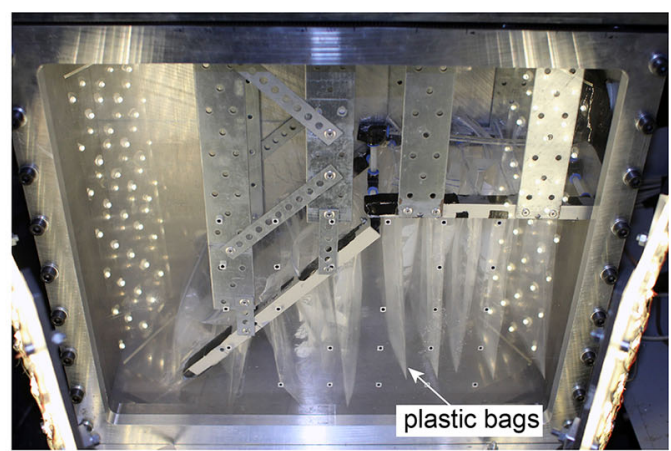

(b)

Fig. 7 Calibration of the rainfall system a setup of the rainfall system in the model box and $\mathbf{b}$ measuring of rainfall intensity of each perforated hose

various $g$ levels. To clarify this debate, the scaling relationship for the flow rate in the introduced rainfall system is examined at an increasing $g$ level ranging from 1 to 40 . To this end, three scenarios with different outlets are tested: (i) the supply mains with $d_{i}=4.0 \mathrm{~mm}$, (ii) the hose of rainwater with $d_{i}=2.5 \mathrm{~mm}$, and (iii) the model rainfall configuration of ten perforated hoses each with 25 I-type pinholes. The discharge and flow rate of the water from different outlet are evaluated by collecting the released water in 30 seconds.

Figure 9 shows the variation in the discharge $q^{*}$ and flow velocity $v$ against the scaling factor $N$. Clearly, the flow rate and discharge are dependent on the size of the orifice and the $g$ level or hydraulic gradient. The calibration tests lead to a scaling factor of $\sqrt{N}$ for the specific discharge and flow rate, which is contradictory to the well-established scaling law of $N$ for fluid flows porous media. However, this discrepancy seems reasonable since the diameter of the hoses is not scaled accordingly with the scaling factor $N$. The same reasoning is given by other studies that observed the same scaling factor of $\sqrt{N}$; that is, a geometric parameter, defining the cross section of the flow, has not been scaled by $N$, e.g. the width of the outlet of a silo [12] or the width of a flow channel $[1,8]$.

\section{Application: rainfall-induced slope failure}

To test the performance of the developed rainfall system, a series of centrifuge tests on rainfall-induced slope failure are carried out. In the following section, the model slope, test program and results are presented. Note that an attempt is not made to study the failure mechanism of the slope under rainfall conditions. This regard is explored in our companion paper [18]. Instead, we are focusing on the performance of the rainfall device.

\subsection{Model slope, test programme and results}

Figure 10a shows the sketch and construction of a homogeneous slope in the centrifuge modelling. Two types of slope with gradients $\beta$ of $35^{\circ}$ and $45^{\circ}$ are adopted in the tests. The slope has a height $h_{\mathrm{sl}}=200 \mathrm{~mm}$ and a base layer with a height $h_{\mathrm{b}}=50 \mathrm{~mm}$. The plane-strain width of the slope is $155 \mathrm{~mm}$. The total length of the slope, including deposition section $l_{1}$, slope section $l_{\mathrm{sl}}$ and crest $l_{2}$, is 480 $\mathrm{mm}$. The deposition section has a length $l_{1}=100$ for depositing of the mobilized sliding mass. The lengths of the slope section and crest are dependent on the slope gradients. For instance, the crest lengths are $95 \mathrm{~mm}$ and $180 \mathrm{~mm}$ for $35^{\circ}$ and $45^{\circ}$ slopes, respectively.

To construct the model slope, a soil cuboid with a dimension of $480 \times 155 \times 250 \mathrm{~mm}(\mathrm{~W} \times \mathrm{D} \times \mathrm{H})$ is firstly made by compacting ten layers of soil with each layer 25 mm thick. The slope is then cut from the compacted soil cuboid. To this end, the front and back walls of the model box are temporarily replaced by wooden molds. Two pairs of wooden mold shown in Fig. 10b with slope angles of $35^{\circ}$ and $45^{\circ}$ are used in this regard. Following the geometries of the wooden molds, it is easy to cut a model slope from the soil cuboid. After the completion of the cutting, some adjustments are needed at the edges of the slope to refine the model slope. Finally, the wooden molds are replaced back with the walls of the model box.

The soil used in the tests is silty medium-fine sand. Figure 11 shows the grain size distribution of the soil. The particle sizes range from $0.002 \mathrm{~mm}$ to $4.0 \mathrm{~mm}$, with a mean grain diameter $d_{50}$ of $0.23 \mathrm{~mm}$. The soil for the slope is compacted at two densities, namely a loose state with $D_{\mathrm{r}}=$ $0.29\left(e_{0}=0.91\right)$ and a medium-dense state with $D_{\mathrm{r}}=0.55$ $\left(e_{0}=0.74\right)$. For each compaction state, two different initial water contents are adopted, i.e. $w_{0}=6.0 \%$ and $11.5 \%$ for loose state and $w_{0}=11.5 \%$ and $15.1 \%$ for mediumdense state. According to the triaxial compression tests, the 


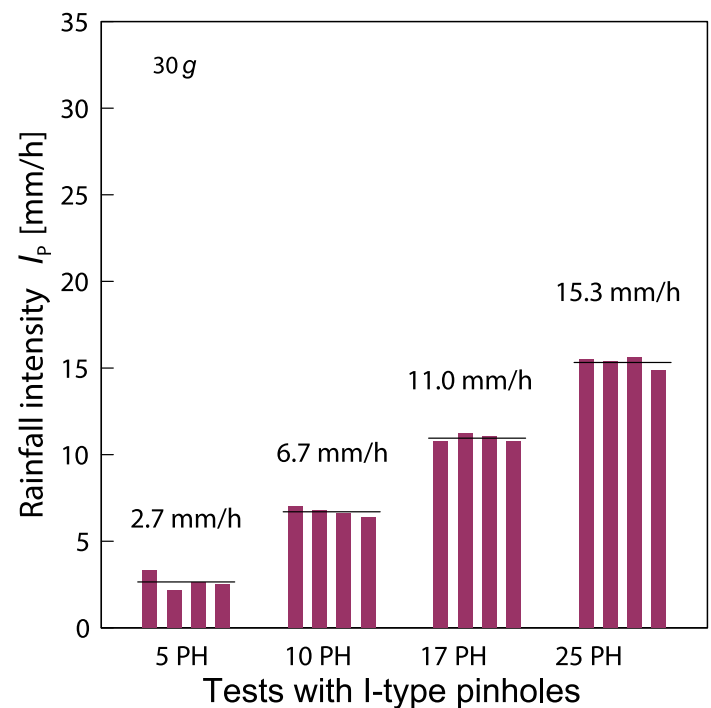

(a)

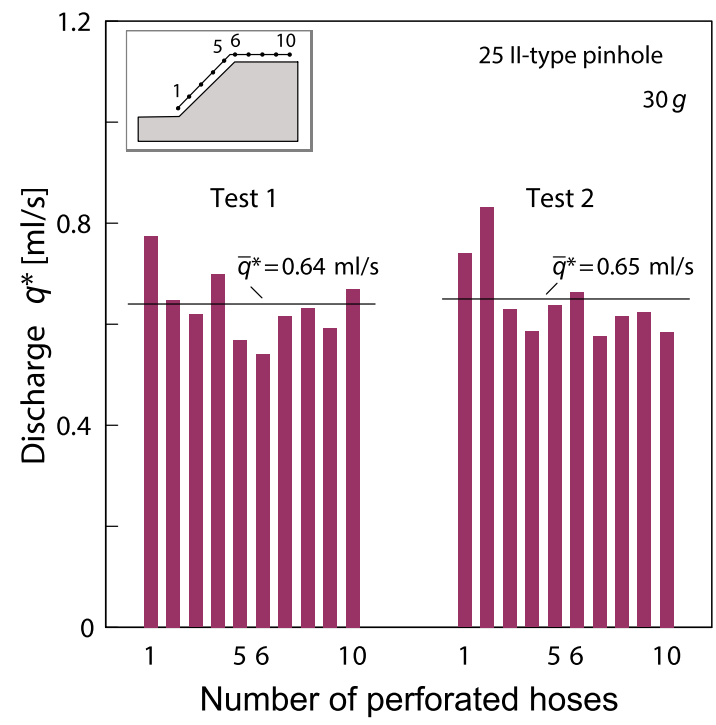

(c)

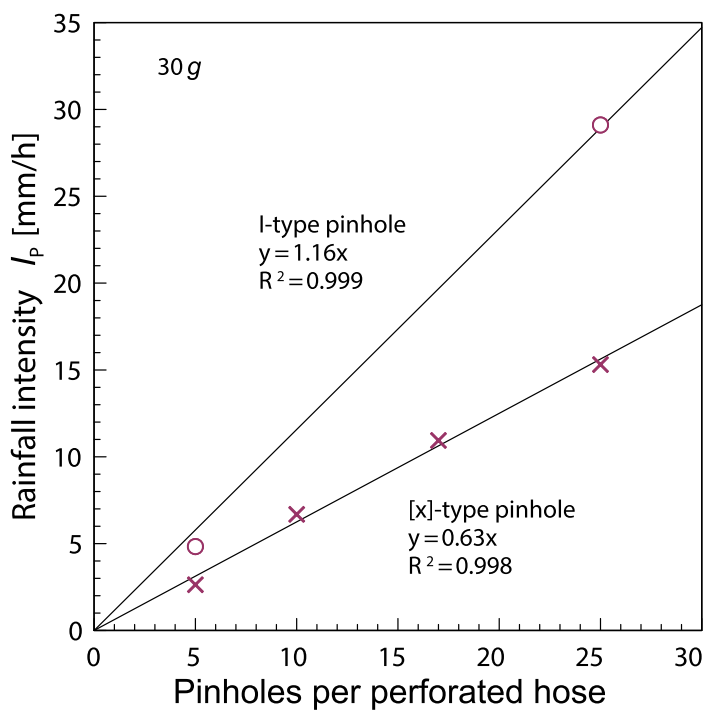

(b)

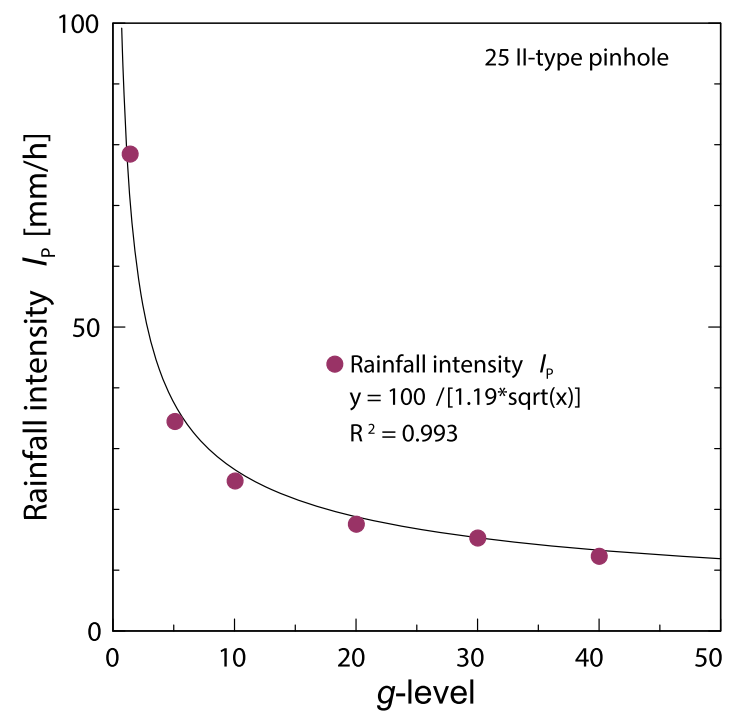

(d)

Fig. 8 Calibration results of the rainfall system: a various rainfall intensities $I_{\mathrm{P}}$ with an increasing number of I-type pinholes, $\mathbf{b}$ linear trend of $I_{\mathrm{P}}$ for an increasing number of pinholes, $\mathbf{c}$ distribution of discharge $q^{*}$ at each perforated hose, and $\mathbf{d}$ the relationship between the rainfall intensity $I_{\mathrm{P}}$ and the $g$-level

Mohr-Coulomb shear parameters of the soil under saturated conditions are $\phi^{\prime}=31.8^{\circ}$ and $c^{\prime}=0.0 \mathrm{kPa}$ for the medium-dense state and $\phi^{\prime}=38.1^{\circ}$ and $c^{\prime}=15.0 \mathrm{kPa}$ for the very dense state $\left(e_{0}=0.51\right)$, respectively. This result shows that the material is a noncohesive soil in regard to the medium-dense state but exhibits considerable apparent cohesion in a very dense state.

In this work, 15 centrifuge tests with the aforementioned initial slope conditions, i.e. slope angle and initial density, are conducted. All the model tests are performed at 30-g level, at which the slope remains initially stable under the enhanced gravity loads. Three types of rainfall intensities, i.e. $I_{\mathrm{P}}=5,12$, and $27 \mathrm{~mm} / \mathrm{h}$, representing moderate, heavy and torrential rainfall events, respectively, at the prototype scale are involved. The rainfall is initiated after the geostatic equilibrium is achieved at the prescribed gravity. The rainfall is persisted for a while after the initial failure. This allows us to observe the subsequent propagation stages of progressive failure.

Details on the initial slope conditions, rainfall characteristics and failure time of the 15 model tests are summarized in Table 2. It should be noted that the actual initial conditions, i.e. the void ratio and water content, of the slopes may be slightly different from the prescribed values 


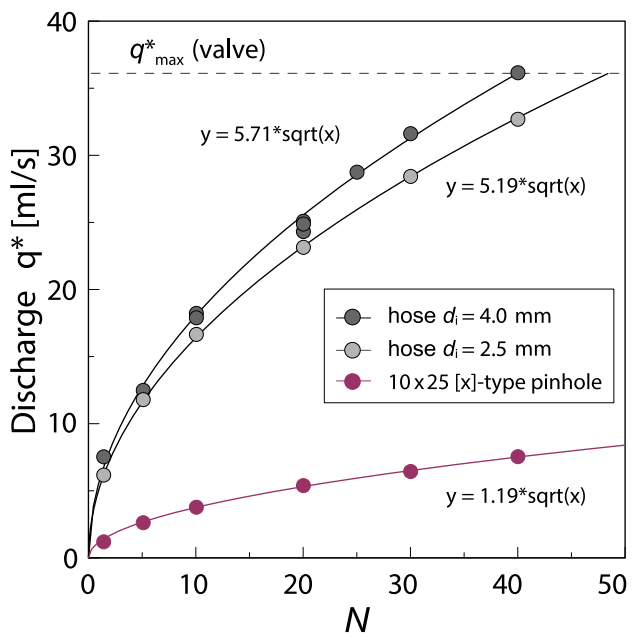

(a)

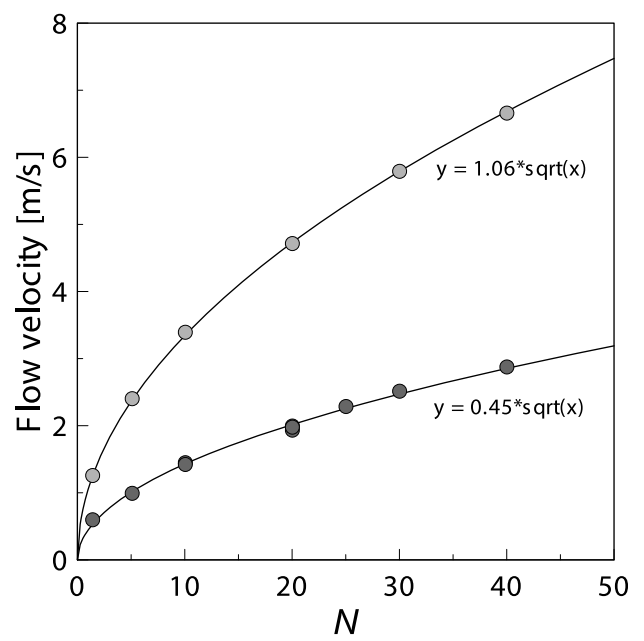

(b)

Fig. 9 Scaling law: a discharge and $\mathbf{b}$ flow velocity of the rainfall system as a function of $N$. The plots represent various orifices: the diameter of the main line (dark grey), the diameter of the perforated hose (light grey), and the rainfall system with the configuration of $10 \times 25$ I-type pinholes $\left(I_{\mathrm{P}}=15 \mathrm{~mm} / \mathrm{h}\right)$

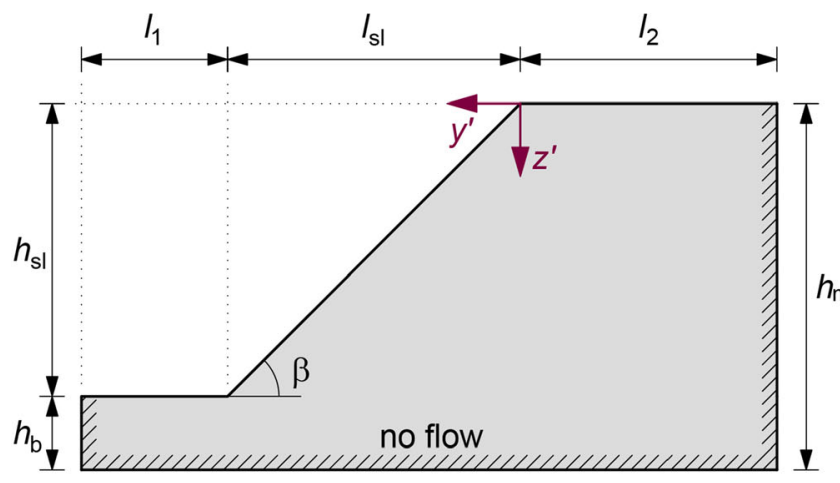

(a)

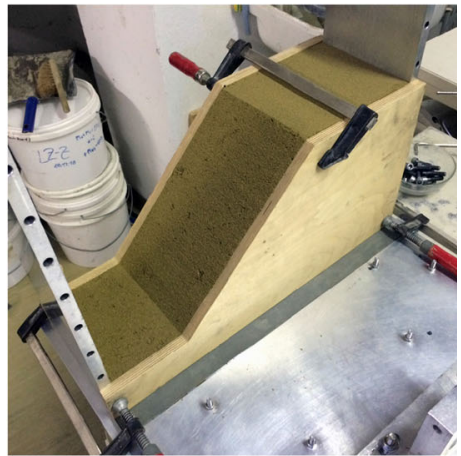

(b)

Fig. 10 a Sketch of a homogeneous model slope and $\mathbf{b}$ construction of a $45^{\circ}$ slope $\left(h_{\mathrm{m}}\right.$ is the model height, $h_{\mathrm{sl}}$ is the height of the slope, $l_{\mathrm{Sl}}$ is the length of the slope, $h_{\mathrm{b}}$ is the height of the base layer, $l_{1}$ and $l_{2}$ are the distances to the sidewalls, and $\beta$ is the slope gradient)

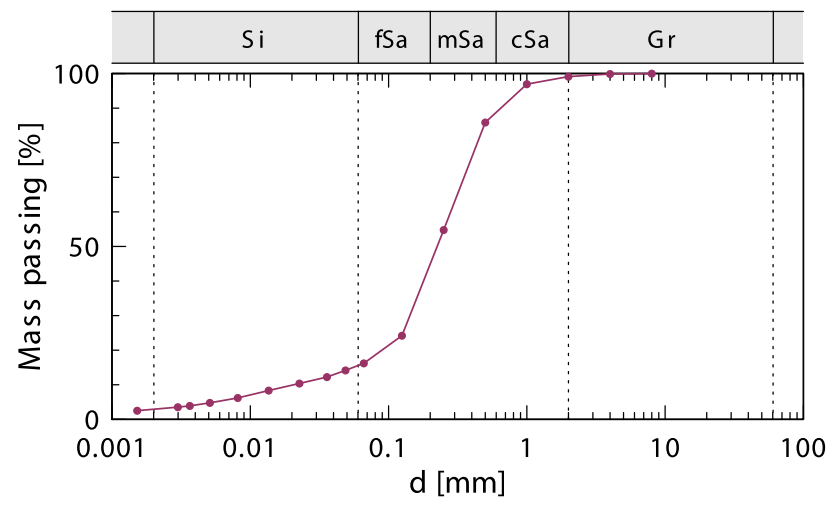

Fig. 11 Grain size distribution curve of the medium-fine sand (Si: silt, fSa: fine sand, mSa: medium sand, cSa: course sand and Gr: gravel) due to the error during slope construction and the preperation of the rainfall system. This situation, however, is very common in physical modelling.

\subsection{Rainfall-induced slope failure}

The rainfall has successfully brought 13 slopes to failure in the centrifuge tests, except the CRF-10 and CRF-12 tests. The results of the rainfall applied to all the model slopes and the hydraulic conditions of the slope soil before and after the test are plotted in Fig. 12.

The rainfall intensity has significant influence on the possible rainfall duration that a slope can withstand. Figure. 12a shows the relationship between the rainfall duration $D_{\mathrm{M}}$ and cumulated rainfall $R_{\mathrm{M}}$. Generally, a slope with denser compaction or lower initial water content is able to withstand longer rainfall. For instance, the moderate 
Table 2 Experimental results of the slope failure under different rainfall intensities

\begin{tabular}{|c|c|c|c|c|c|c|c|c|c|}
\hline \multirow[b]{2}{*}{ Test ID } & \multirow[b]{2}{*}{$\begin{array}{l}g \text {-level } \\
{[g]}\end{array}$} & \multicolumn{3}{|c|}{ Initial slope conditions } & \multicolumn{3}{|l|}{ Rainfall } & \multicolumn{2}{|c|}{ Failure time } \\
\hline & & $\begin{array}{l}\beta \\
{[\mathrm{deg}]}\end{array}$ & $\begin{array}{l}e_{0} \\
{[-]}\end{array}$ & $\begin{array}{l}w_{0} \\
{[\%]}\end{array}$ & $\begin{array}{l}I_{\mathrm{P}} \\
{[\mathrm{mm} / \mathrm{h}]}\end{array}$ & $\begin{array}{l}D_{\mathrm{M}} \\
{[\mathrm{s}]}\end{array}$ & $\begin{array}{l}R_{\mathrm{M}} \\
{[\mathrm{ml}]}\end{array}$ & $\begin{array}{l}t_{\mathrm{f}, \mathrm{M}} \\
{[\mathrm{s}]}\end{array}$ & $\begin{array}{l}t_{\mathrm{f}, \mathrm{P}} \\
{[\mathrm{hh}: \mathrm{mm}]}\end{array}$ \\
\hline CRF-01 & 30 & 45 & 0.91 & 6.0 & 14.8 & 106 & 728 & 19 & 04:47 \\
\hline CRF-02 & 30 & 45 & 0.91 & 6.0 & 15.9 & 180 & 1059 & 13 & $03: 17$ \\
\hline CRF-03 & 30 & 45 & 0.91 & 11.5 & 11.8 & 96 & 523 & 35 & $10: 04$ \\
\hline CRF-04 & 30 & 45 & 0.91 & 11.6 & 10.5 & 103 & 498 & 14 & $03: 32$ \\
\hline CRF-05 & 30 & 45 & 0.76 & 11.3 & 10.1 & 150 & 702 & 55 & $15: 06$ \\
\hline CRF-06 & 30 & 45 & 0.75 & 11.3 & 10.0 & 210 & 967 & 154 & $38: 47$ \\
\hline CRF-07 & 30 & 45 & 0.73 & 14.7 & 11.6 & 130 & 699 & 26 & $06: 32$ \\
\hline CRF-08 & 30 & 45 & 0.72 & 11.3 & 27.0 & 60 & 749 & 4 & 01:00 \\
\hline CRF-09 & 30 & 45 & 0.73 & 15.0 & 5.8 & 320 & 859 & 94 & $23: 48$ \\
\hline CRF-10 & 30 & 45 & 0.74 & 11.5 & 4.9 & 410 & 924 & - & - \\
\hline CRF-11 & 30 & 35 & 0.91 & 6.3 & 13.2 & 140 & 852 & 36 & 09:04 \\
\hline CRF-12 & 30 & 35 & 0.90 & 11.5 & 12.0 & 220 & 1224 & - & - \\
\hline CRF-13 & 30 & 35 & 0.74 & 11.5 & 12.6 & 325 & 1897 & 254 & 64:09 \\
\hline CRF-14 & 30 & 35 & 0.75 & 15.1 & 12.9 & 110 & 655 & 38 & $10: 19$ \\
\hline CRF-15 & 30 & 35 & 0.87 & 11.5 & 13.5 & 230 & 1433 & 51 & $12: 50$ \\
\hline
\end{tabular}

The subscripts $\mathrm{M}$ and $\mathrm{P}$ denote model and prototype scale, respectively

$\beta$ is slope angle, $e_{0}$ initial void ratio, $w_{0}$ initial water content, $I$ rainfall intensity, $D$ rainfall duration and $R$ accumulated rainfall, $t_{\mathrm{f}}$ initial failure time, - without failure.

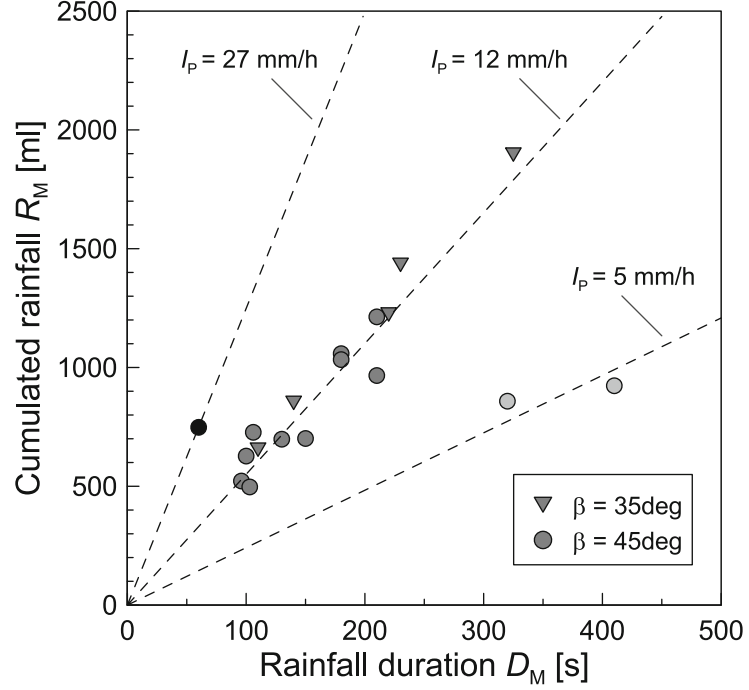

(a)

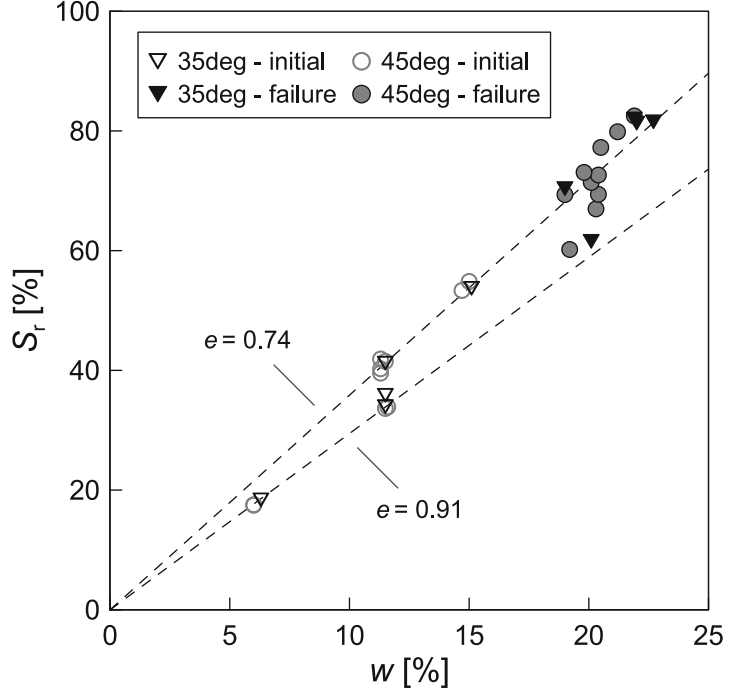

(b)

Fig. 12 Test results a the rainfall characteristics and $\mathbf{b}$ the hydraulic conditions water content $w$ and degree of saturation $S_{r}$ ) at initial and failure stage

rainfall of approximately $5 \mathrm{~mm} / \mathrm{h}$ initiates slope failure after $94 \mathrm{~s}$, or approximately $24 \mathrm{~h}$ at the prototype scale, for the medium-dense slope inclined at $45^{\circ}$ (CRF-09). The same slope, only with a lower initial degree of saturation, does not experience any failure after a rainfall duration of approximately $410 \mathrm{~s}$ or more than 4 days at the prototype scale (CRF-10). This highlights that the soil saturation plays an important role in stabilizing the slope under rainfall events. The heavy rainfall of approximately 12 $\mathrm{mm} / \mathrm{h}$ is applied to seven slopes inclined at $45^{\circ}$ and five slopes inclined at $35^{\circ}$. Depending on the initial void ratio and initial degree of saturation, the rainfall durations causing initial failure range from 12 - $154 \mathrm{~s}$ ( $3 \mathrm{~h}$ to 1.5 days for the prototype) for $45^{\circ}$ slopes and from $36-254 \mathrm{~s}$ ( $9 \mathrm{~h}$ to 


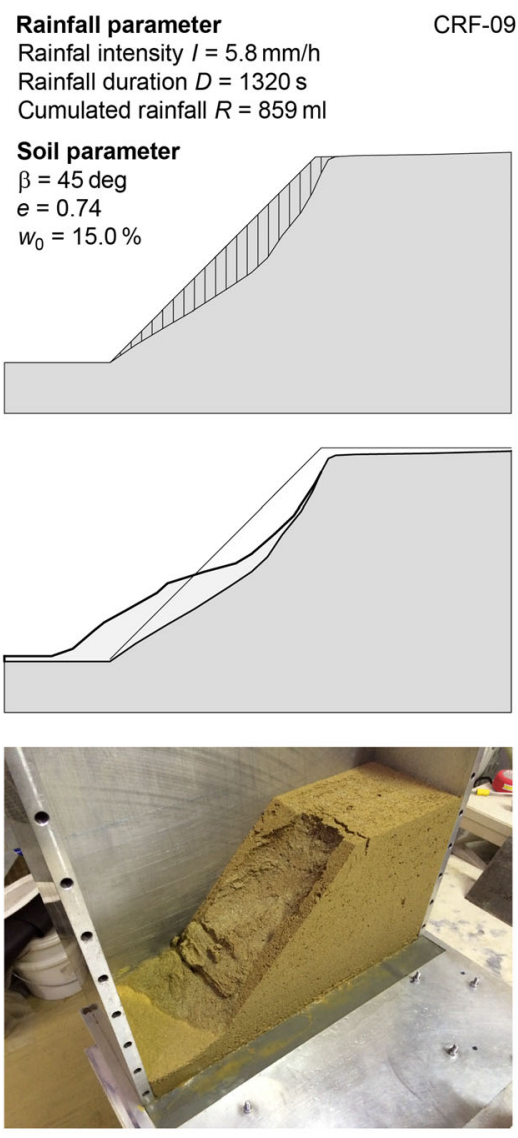

(a)
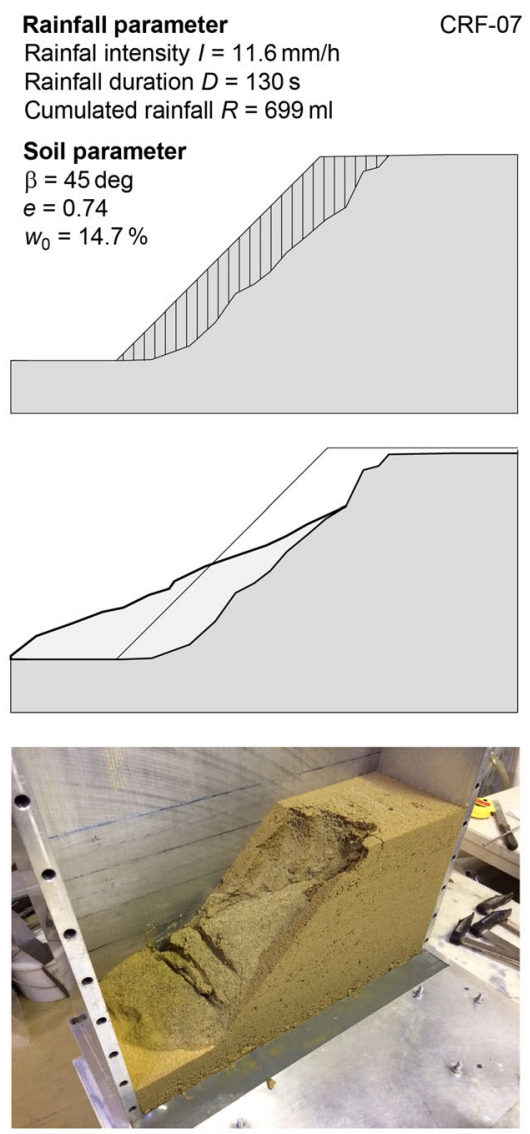

(b)
Rainfall parameter
Rainfal intensity $I=27.0 \mathrm{~mm} / \mathrm{h}$
Rainfall duration $D=60 \mathrm{~s}$

Cumulated rainfall $R=749 \mathrm{ml}$

Soil parameter

$\beta=45$ deg

$e=0.74$

$w_{0}=11.3 \%$

CRF-08
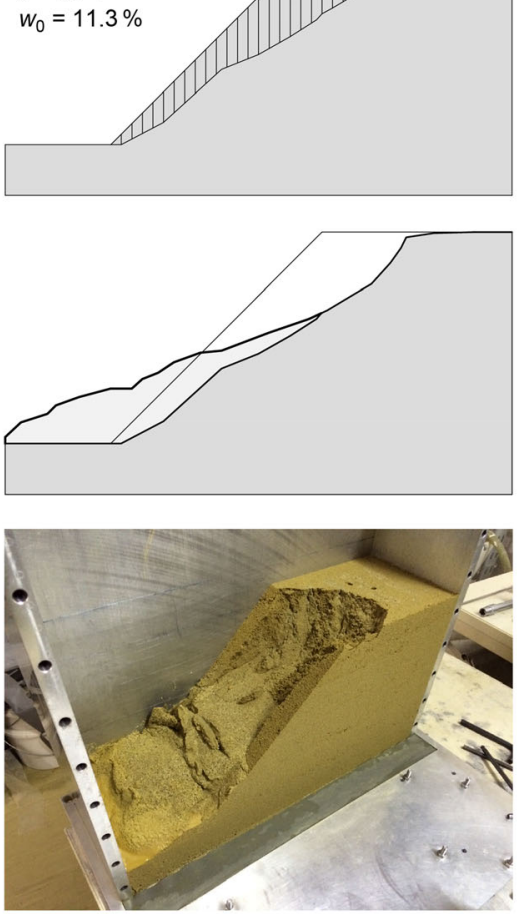

(c)

Fig. 13 Pictures and sketched origin and deposition of the slope failure under different rainfall intensities: $\mathbf{a}$ test CRF-09 with $I_{\mathrm{P}}=5.8 \mathrm{~mm} / \mathrm{h}, \mathbf{b}$ test CRF-07 with $I_{\mathrm{P}}=11.6 \mathrm{~mm} / \mathrm{h}$ and $\mathbf{c}$ test CRF-08 with $I_{\mathrm{P}}=27.0 \mathrm{~mm} / \mathrm{h}$

2.7 days for the prototype) for $35^{\circ}$ slopes. The torrential rainfall of approximately $27 \mathrm{~mm} / \mathrm{h}$ in test CRF-08 triggers the fastest failure among all tests. The rainfall duration is only approximately $4 \mathrm{~s}$, or approximately $1 \mathrm{~h}$ at the prototype scale.

Figure $12 \mathrm{~b}$ gives the hydraulic state conditions, i.e. water content $w$ and degree of saturation $S_{\mathrm{r}}$, of the slopes at initial and failure stage. The water content at post-failure stage is measured from the soil at the centre of the slope crest. Although these slopes are prepared at different initial water contents, they seem to fail at a similar water content of approximately $20 \%$, which corresponds to the degree of saturation of $60 \%$ and $80 \%$ for medium-dense and very dense states, respectively. It can be speculated that when the saturation of the soil is increased to this extent, the capillary forces become insufficient to maintain the slope stable, and thus, catastrophic failure of the slope may occur.

Figure 13 illustrates some typical examples of the failed slopes with sketched origin and deposition. These slopes are constructed with the same density and slope angle, but the slope soils have different initial water contents. Subjected to different rainfall intensities, i.e. $I_{P}=5,12$ and
$27 \mathrm{~mm} / \mathrm{h}$, these slopes exhibit different failure patterns, such as global slides and sliding flow, with the generation of a significant displacement. As shown in Fig. 13a, the slope initiated by moderate rainfall of $5 \mathrm{~mm} / \mathrm{h}$ gives rise to a more superficial failure surface and results in much a shorter runout distance. Compared to the moderate rainfall events, e.g. test CRF-09, a deeper failure surface could be observed for heavy rainfall (see Fig. 13b). The slope in test CRF-08 fails immediately after a few seconds of torrential rainfall. A fast flow of soil is initiated from the top of the slope with high degree of saturation under such heavy rainfall. The short duration of torrential rainfall also causes the increase in water level at the toe, which may contribute to the loss of suction in the slope soil [5]. It is believed that a uniform infiltration deep into the slope body has not yet been established during such a short time. Thus, the torrential rainfall may lead to slope failure of flow type [4], initiated mainly by surface erosion (see Fig. 13c). However, our experiments show that the moderate and heavy rainfall leads to less erosion. Another aspect lies on the rainfall distribution. Since the perforated hoses are distributed with a spacing of $35 \mathrm{~mm}$, this may lead to 
localized infiltration in these regions below the hoses. However, this does not influence significantly the failure types of the slope.

\section{Conclusions}

This work presents a device for simulating rainfall in geotechnical centrifuge. The rainfall system adopts the principle of drip irrigation usually used in agriculture. An array of perforated hoses is placed close above the slope surface to discharge the rainwater. The rainfall intensity depends on the centrifuge acceleration and the flow rate of the water supply, which is controlled by the size and number of the tiny pinholes in the hose walls. A wide range of rainfall intensities from $2.5-30 \mathrm{~mm} / \mathrm{h}$ can be simulated by this device. The perforated hoses are distributed following the geometry of the slope, and thus the flow rates of all the perforated hose show considerable consistency over the slope surface. In this way, check valves for adjusting the flow rates at different slope elevation are not required in this rainfall system. Moreover, with only $10 \mathrm{~mm}$ falling height, the influence of Coriolis force and the high-speed wind on the raindrops and their impact force on the slope surface can be neglected.

The performance of the rainfall system is evaluated by carrying out a series of centrifuge tests on rainfall-induced slope failure. The tests involves 15 homogeneous soil slopes with different initial conditions, such as slope angle, initial water content and density. These slopes are subjected to $30-\mathrm{g}$ gravity loads and three types of rainfall intensities, namely $I_{\mathrm{P}}=5,12$, and $27 \mathrm{~mm} / \mathrm{h}$, representing moderate, heavy and torrential rainfall events, respectively, at the prototype scale. The test results suggest that the device is able to generate relatively uniform rainfall of wide intensities and lead to slope failure of various patterns. The new device is simple, robust and affordable. This can be of particular interest for centrifuge facilities that have a lack of space for supply lines of pressurized water.

Acknowledgements Open access funding was provided by the University of Natural Resources and Life Sciences Vienna (BOKU). This work was funded by the Otto Pregl Foundation project "Kriechhänge".

Funding Open access funding provided by University of Natural Resources and Life Sciences Vienna (BOKU).

Open Access This article is licensed under a Creative Commons Attribution 4.0 International License, which permits use, sharing, adaptation, distribution and reproduction in any medium or format, as long as you give appropriate credit to the original author(s) and the source, provide a link to the Creative Commons licence, and indicate if changes were made. The images or other third party material in this article are included in the article's Creative Commons licence, unless indicated otherwise in a credit line to the material. If material is not included in the article's Creative Commons licence and your intended use is not permitted by statutory regulation or exceeds the permitted use, you will need to obtain permission directly from the copyright holder. To view a copy of this licence, visit http://creativecommons. org/licenses/by/4.0/.

Data availability statement The datasets generated during and/or analysed during the current study are available from the corresponding author on reasonable request.

\section{References}

1. Cabrera MA, Wu W (2017) Experimental modelling of freesurface dry granular flows under a centrifugal acceleration field. Granular Matter 19(4):78

2. Caicedo B, Tristancho J (2010) A virtual rain simulator for droplet transport in a centrifuge. In Proceedings of the 7th International Conference on Physical Modelling in Geotechnics (ICPMG 2010), Zurich, 99

3. Caicedo B, Tristancho J, Thorel L (2015) Mathematical and physical modelling of rainfall in centrifuge. Int J Phys Model Geotechn 15(3):150-164

4. Cascini L, Cuomo S, Pastor M, Sacco C (2013) Modelling the post-failure stage of rainfall-induced landslides of the flow type. Can Geotech J 50(9):924-934

5. Chen YM, Li JC, Yang CB, Zhu B, Zhan LT (2017) Centrifuge modeling of municipal solid waste landfill failures induced by rising water levels. Can Geotech J 54(12):1739-1751

6. Eab KH, Takahashi A, Likitlersuang S (2014) Centrifuge modelling of root-reinforced soil slope subjected to rainfall infiltration. Géotech Lett 4(3):211-216

7. Hung WY, Tran MC, Yeh FH, Lu CW, Ge L (2020) Centrifuge modeling of failure behaviors of sandy slope caused by gravity, rainfall, and base shaking. Eng Geol 271:105609

8. Kailey P (2013) Debris flows in New Zealand alpine catchments. $\mathrm{PhD}$ thesis, University of Canterbury

9. Kimura K (1991) Failure of fills due to rain fall. In Centrifuge, 91:509-516. Balkema

10. Ling H, Ling HI (2012) Centrifuge model simulations of rainfallinduced slope instability. J Geotech Geoenviron Eng 138(9):1151-1157

11. Ling HI, Wu MH, Leshchinsky D, Leshchinsky B (2009) Centrifuge modeling of slope instability. J Geotech Geoenviron Eng 135(6):758-767

12. Mathews JC, Wei W (2016) Model tests of silo discharge in a geotechnical centrifuge. Powder Tech 293:3-14

13. Take WA, Beddoe RA (2014) Base liquefaction: a mechanism for shear-induced failure of loose granular slopes. Can Geotech J 51(5):496-507

14. Take WA, Bolton MD, Wong PCP, Yeun FJ (2004) Evaluation of landslide triggering mechanisms in model fill slopes. Landslides 1(3): 173-184

15. Take WA (2003) The influence of seasonal moisture cycles on clay slopes. PhD thesis, University of Cambridge, Cambridge

16. Tamate S, Suemasa N, Katada T (2012) Simulation of precipitation on centrifuge models of slopes. Int J Phys Model Geotech 12(3):89-101

17. Taylor RN (2018) Centrifuges in modelling: principles and scale effects. Geotechn Centrif Tech. CRC Press, Florida, pp 19-33

18. Wang S, Idinger G, Wu W (2021) Centrifuge modelling of rainfall-induced slope failure in variably saturated soil. Acta Geotech. https://doi.org/10.1007/s11440-021-01169-x

Publisher's Note Springer Nature remains neutral with regard to jurisdictional claims in published maps and institutional affiliations. 